\title{
Fiber Optical Micro-detectors for Oxygen Sensing in Power Plants
}

Quarterly Technical Progress Report Reporting Period:

October 1, 2002 to December 31, 2002

\author{
Gregory L. Baker ${ }^{*}$, Ruby N. Ghosh ${ }^{+}$, D.J. Osborn III ${ }^{*}$ \\ January 2003 \\ DOE Award Number: DE-FC26-02NT41582 \\ *536 Chemistry Building, Department of Chemistry \\ +2167 BPS, Center for Sensor Materials \\ Michigan State University \\ East Lansing, MI 48824
}




\title{
DISCLAIMER
}

"This report was prepared as an account of work sponsored by an agency of the United States Government. Neither the United States Government nor any agency thereof, nor any of their employees, makes warranty, express or implied, or assumes any legal liability or responsibility for the accuracy, completeness, or usefulness of any information, apparatus, product, or process disclosed, or represents that its use would not infringe privately owned rights. Reference herein to any specific commercial product, process, or service by trade name, trademark, manufacturer, or otherwise does not necessarily constitute or imply its endorsement, recommendation, or favoring by the United States Government or any agency thereof. The views and opinions of the authors expressed herein do not necessarily state or reflect those of the United States Government or any agency thereof."

\begin{abstract}
In this report, initial results pertaining to the synthesis molybdenum clusters and characterization using absorption, optical microscopy, and x-ray powder diffraction are discussed. The synthesis was performed according to literature [1], but results from x-ray powder diffraction indicate that the synthesis did not give the desired compound. The absorption and optical microscopy indicate that the compound synthesized has properties similar to the desired $\mathrm{Mo}_{6} \mathrm{Cl}_{12}$ clusters [2,3], so it is unclear as of yet what happened. The sample cell for performing high temperature spectroscopy on thin films of the molybdenum clusters at elevated temperature in a controlled gas environment was designed and an initial prototype was built.
\end{abstract}




\section{TABLE OF CONTENTS}

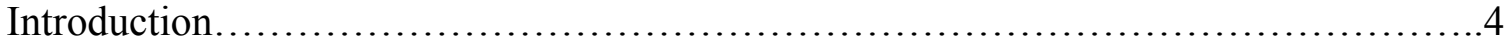

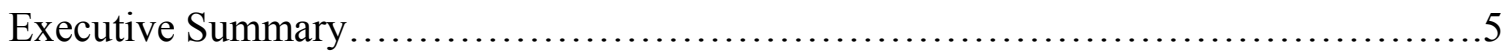

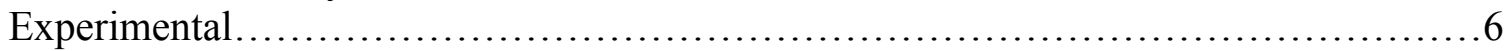

Synthesis........................................................6

Absorption.............................................................6

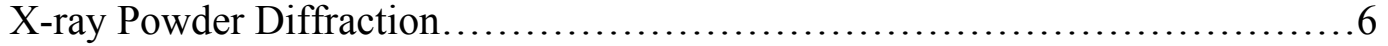

Optical microscopy...................................................6 6

Results and Discussion...................................................... 7

Absorption................................................................

X-ray Powder Diffraction............................................... 8

Microscopy............................................................ 8

Quartz Sample Cell for High Temperature Spectroscopy......................10

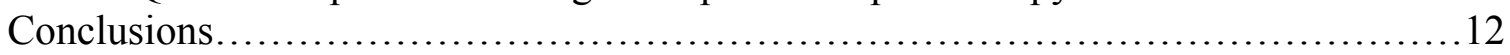

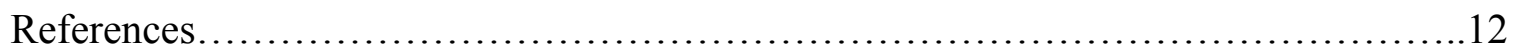

Bibliography............................................................... 12

List of Acronyms and Abbreviations............................................... 12

Appendix A....................................................................

\section{LIST(S) OF GRAPHICAL MATERIALS}

Figure 1. Absorption measurements at room temperature for a) current (DJO6-1) $\mathrm{Mo}_{6} \mathrm{Cl}_{12}$ in $\mathrm{MeOH}, \mathrm{b}$ ) current (DJO8-1) $\mathrm{Mo}_{6} \mathrm{Cl}_{12}$ in $\mathrm{CH}_{3} \mathrm{CN}$, and c) previously synthesized (DJO93) $\mathrm{Mo}_{6} \mathrm{Cl}_{12}$ in $\mathrm{MeOH}$.

Figure 2. Absorption and emission spectra [2] of $\mathrm{Mo}_{6} \mathrm{X}_{14}{ }^{2-}$ ions, as tetrabutylammonium salts in $\mathrm{CH}_{3} \mathrm{CN}$ at room temperature: a) $\mathrm{Mo}_{6} \mathrm{Cl}_{14}{ }^{2-}, \mathrm{Mo}_{6} \mathrm{Br}_{14}{ }^{2-}$; b) $\mathrm{W}_{6} \mathrm{Cl}_{14}{ }^{2-}, \mathrm{W}_{6} \mathrm{Br}_{14}{ }^{2-}$, $\mathrm{W}_{6} \mathrm{I}_{14}{ }^{2-}$.

Figure 3. X-ray powder diffraction patterns of current $\mathrm{Mo}_{6} \mathrm{Cl}_{12}$ and previously synthesized $\mathrm{Mo}_{6} \mathrm{Cl}_{12}$.

Figure 4. Optical microscope image of currently synthesized $\mathrm{Mo}_{6} \mathrm{Cl}_{12}$.

Figure 5. Schematic of quartz sample cell for high temperature spectroscopy. 


\section{INTRODUCTION}

Maximizing the efficiency of the combustion process requires maintaining the correct mixture of oxygen and fuel. This requires quick response time and the ability to sense oxygen levels over a broad range of concentrations.

Mussell, Newsham, and Ruud have already done some of the preliminary work related to this project $[1,2,3]$ in their theses. Mussell describes a procedure for the synthesis of the molybdenum clusters. Newsham gives a good account of the properties of the molybdenum clusters as their salts, and as the neutral compound in both solution and a sol gel matrix. Those results indicate that the clusters will maintain their photophysical properties while in the sol gel. Ruud developed a process to immobilize the clusters in poly[1-trimethylsilyl-1-propyne] (PTMSP), and devised a dipping technique to coat the composite at the cleaved end of a silica optical fiber. Ghosh and co-workers [4] demonstrated a fast room temperature fiber optic sensor by utilizing the fluorescence quenching of the luminescence. The previously used polymeric support adequate for room temperature applications, is unable to withstand the higher temperatures that accompany combustion in a power plant. To improve upon that same device scheme, we are fabricating similar devices using the sol gel matrix as the $\mathrm{Mo}_{6} \mathrm{Cl}_{12}$ cluster support. The sol gel matrix should be able to withstand the higher temperature requirements of the power plant combustion process. The idea of using a sol gel as the support matrix for high temperature oxygen sensor application is not new. Remillard and coworkers have shown that a sol gel supported copper based oxygen sensor can be used in a combustion process [5]. With these facts in hand, we anticipate promising results from our design. 


\section{EXECUTIVE SUMMARY}

The initial synthesis attempt seems to have given a compound with promising absorption characteristics. Optical microscopy indicates that the compound is of the same color and crystallinity. The x-ray powder diffraction data has given ambiguous results however, and this is somewhat troubling.

The x-ray powder diffraction pattern is somewhat of a mystery. The other results look promising, as far as having the right compound, but the x-ray data does not look right $[6,7]$. Probably the most disconcerting aspect is the fact that the powder pattern indicates an amorphous compound while the polarized microscopy indicates crystallinity. Because structure plays such an important role in the chemistry of compounds, this problem is not trivial. We need to know that we have made the correct compound. If we did not make the right compound, we need to know what went wrong. We continue to search the literature for insight into this discrepancy, and will also repeat our experiments to confirm that our results are reproducible. We have a small amount of sample leftover from previous work that will be used for comparison.

In addition to the above, we have begun working on the sol gel synthesis using procedures optimized and studied by MacCraith and coworkers [8,9]. Remillard and coworkers have shown that the typical dip-coating technique produced non-uniform silica sol beads on the end of an optical fiber [5]. They devised an interesting approach for applying a sol-gel / fluorophore slurry to the end of an optical fiber. The approach utilizes a Paasche double-action, internal mix airbrush. The technique allowed them to apply $20-30 \mu \mathrm{m}$ thick layers of sol gel slurry that were uniform across the end of the fiber. The layers that are produced by dip or spin coating are thinner, but we should still see good oxygen quenching results. The ease of applying the slurry to the substrate using the airbrush technique also makes this a particularly attractive approach.

In phase one of this project we will measure the high temperature photophysical properties of the molybdenum cluster in the form of thin films. To this end a quartz cell for making absorption and emission measurements in a controlled gaseous ambient and fixed temperature (up to at least $200^{\circ} \mathrm{C}$ ) was designed and built. Initial testing indicates the need to re-design the electrical wiring for the sample heater. 


\section{EXPERIMENTAL}

\section{Synthesis}

The synthesis of molybdenum clusters was attempted using previous techniques [1]. $\mathrm{MoCl}_{2}(1.10 \mathrm{~g}, 6.62 \mathrm{mmol})$ from Cerac was dissolved in $6 \mathrm{M} \mathrm{HCl}$ with heating. The volume was then reduced to $1 / 4$ and allowed to cool. Upon cooling, long yellow needles crystallized out. The solution was filtered and the collected crystals placed in a Schlenk tube. The crystals were then heated under vacuo at $150{ }^{\circ} \mathrm{C}$ for 2.5 hours. The flask was cooled and placed under argon. The crystals were then crushed and placed back under vacuum at $212{ }^{\circ} \mathrm{C}$ for 6 hours to obtain an orange-yellow powder.

\section{Absorption}

The absorption measurements were performed using a Perkin-Elmer Lambda 40 series double beam uv-vis spectrometer. Data analysis was performed using the UV Win lab (version2.80.03) software package supplied with the instrument. The solvents used were HPLC grade methanol from Spectrum and anhydrous Acetonitrile from Aldrich. Argon was bubbled through the solvents at a rate of $10 \mathrm{~mL} / \mathrm{min}$ for 20 minutes to minimize oxygen quenching.

\section{X-ray powder diffraction}

Samples were prepared by first placing a small piece of double sided tape on top of a microscope slide. Using a spatula, a small amount of powdered sample was then placed on top of the tape and spread around to evenly distribute. Once spread evenly, the powder was pressed gently to insure that the sample was stuck to the tape. The microscope slide was gently tapped on its side to knock off any loose powder that might get into the goniometer.

\section{Optical microscopy}

A small amount of sample was placed onto a microscope slide and viewed under polarized and non-polarized light. The microscope used was a Nikon Optiphot2-Pol equipped with a Sony Hyper HAD CCD-IRIS/RGB color video camera (model DXC151A). The camera was connected to a PC using a Sony camera adapter (model CMAD2). The images were viewed using a Sony Trinitron color video monitor. Images were taken using Hauppage computer works Win/TV software (version 2.4.17052). 


\section{$\underline{\text { RESULTS AND DISCUSSION }}$}

\section{Absorption}

In figure 1 , the absorption spectra of freshly synthesized $\mathrm{Mo}_{6} \mathrm{Cl}_{12}$ in $\mathrm{MeOH}$ and $\mathrm{CH}_{3} \mathrm{CN}$ are plotted along with results using previously synthesized $\mathrm{Mo}_{6} \mathrm{Cl}_{12}$ in $\mathrm{MeOH}$. It is evident that the peak shapes are the same, but the intensities are different due to concentration differences. It has been shown by the Nocera group [1,2] that ligands have little affect other than attenuation of the signal for $\mathrm{Mo}_{6} \mathrm{Cl}_{12}$ based fluorophores. It has also been shown that the tetraalkylammonium salts give spectra similar to the neutral compound. The absorption spectra for the tetraalkylammonium salts of $\mathrm{Mo}_{6} \mathrm{Cl}_{12}$ in figure 2 are also similar, which provides further evidence that we have obtained the correct compound.

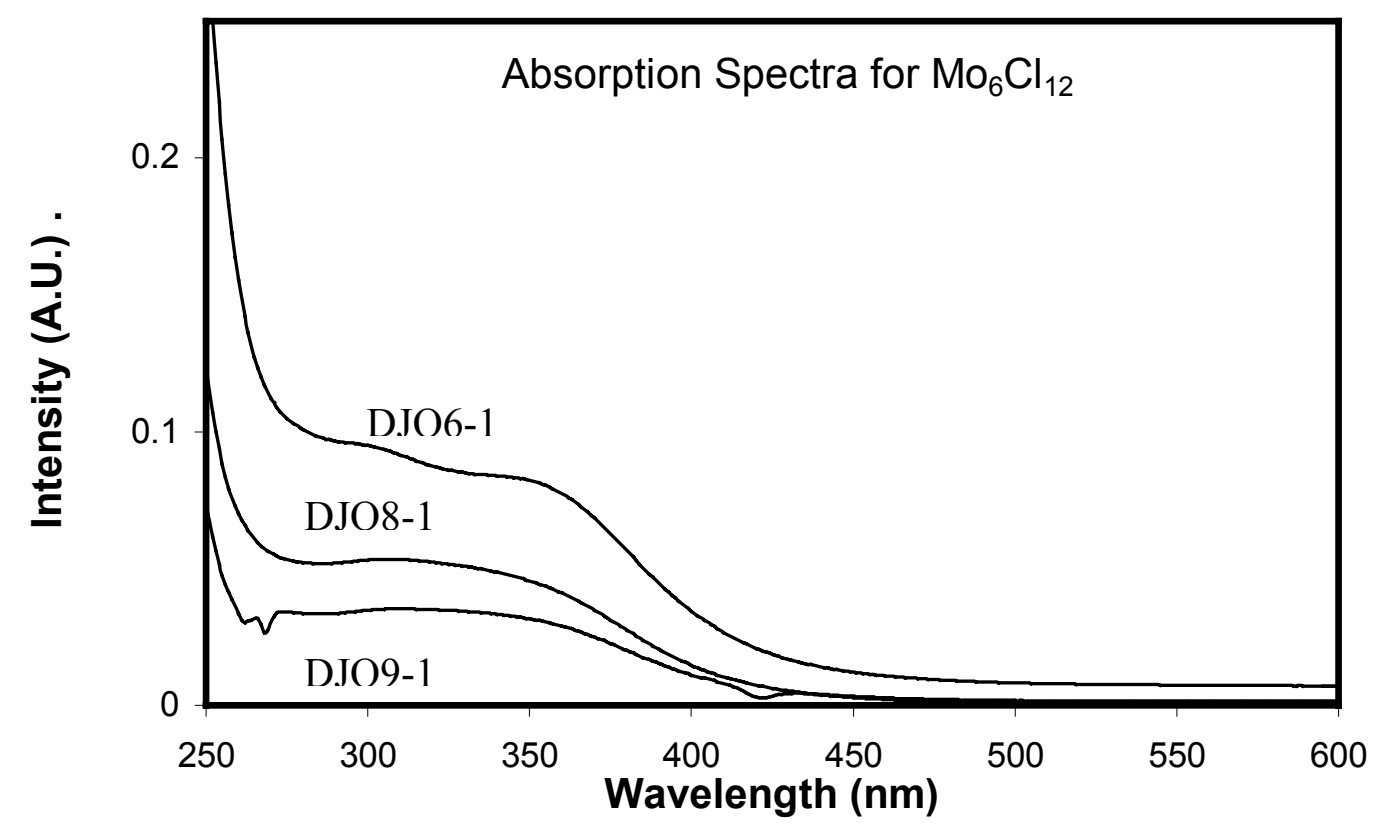

Figure 1. Absorption measurements at room temperature for a) current (DJO6-1) $\mathrm{Mo}_{6} \mathrm{Cl}_{12}$ in $\mathrm{MeOH}, \mathrm{b}$ ) current (DJO8-1) $\mathrm{Mo}_{6} \mathrm{Cl}_{12}$ in $\mathrm{CH}_{3} \mathrm{CN}$, and c) previously synthesized (DJO9-3) $\mathrm{Mo}_{6} \mathrm{Cl}_{12}$ in $\mathrm{MeOH}$. 


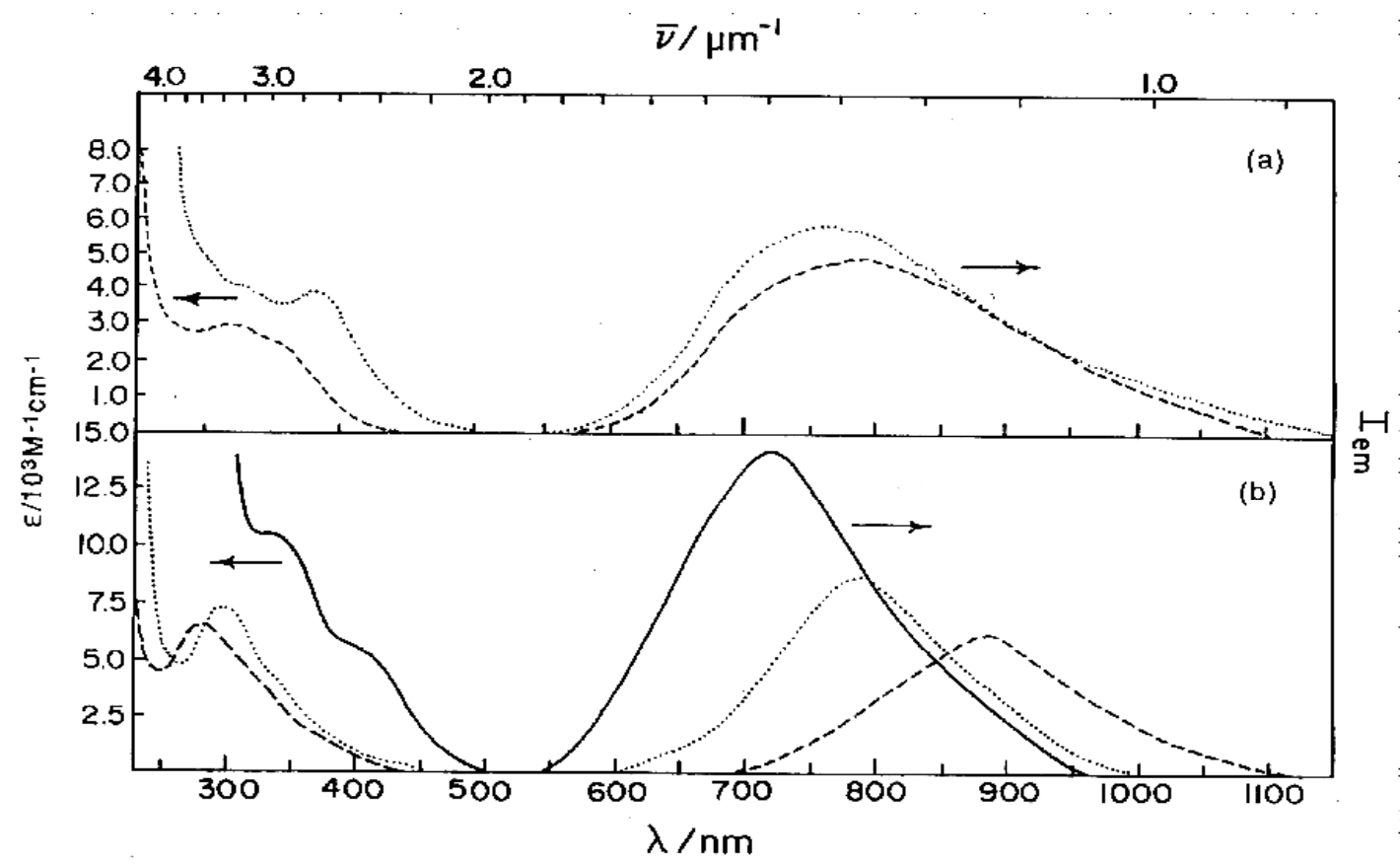

Figure 2. Absorption and emission spectra [2] of $\mathrm{Mo}_{6} \mathrm{X}_{14}{ }^{2-}$ ions, as tetrabutylammonium salts in $\mathrm{CH}_{3} \mathrm{CN}$ at room temperature: a) $\mathrm{Mo}_{6} \mathrm{Cl}_{14}{ }^{2-}, \mathrm{Mo}_{6} \mathrm{Br}_{14}{ }^{2-}$; b) $\mathrm{W}_{6} \mathrm{Cl}_{14}{ }^{2-}, \mathrm{W}_{6} \mathrm{Br}_{14}{ }^{2-}, \mathrm{W}_{6} \mathrm{I}_{14}{ }^{2-}$.

\section{X-ray Powder diffraction and Optical Microscopy}

The results of the $x$-ray powder diffraction, figure 3 , indicate a serious difference in the currently synthesized compound structure when compared to the pattern obtained from the previously synthesized compound. The pattern of the current compound shows that it is different, even though it has the same absorption and emission spectra. The pattern also indicates that the compound synthesized is amorphous. The character of the compound was further investigated via optical microscopy using polarized light. An image of the crystals is shown in figure 4 . The image shows a compound consisting of rod like crystallites approximately $150 \mu \mathrm{m}$ x $20 \mu \mathrm{m}$ in size. Thus far, it has not been determined what happened, but it is obvious that the freshly synthesized compound is not of the same structure as previously obtained. Further experiments are needed in order to solve this puzzle. The compound will be resynthesized to insure that it is not due to experimental problems. We will also continue to search the literature for insight into what happened. 


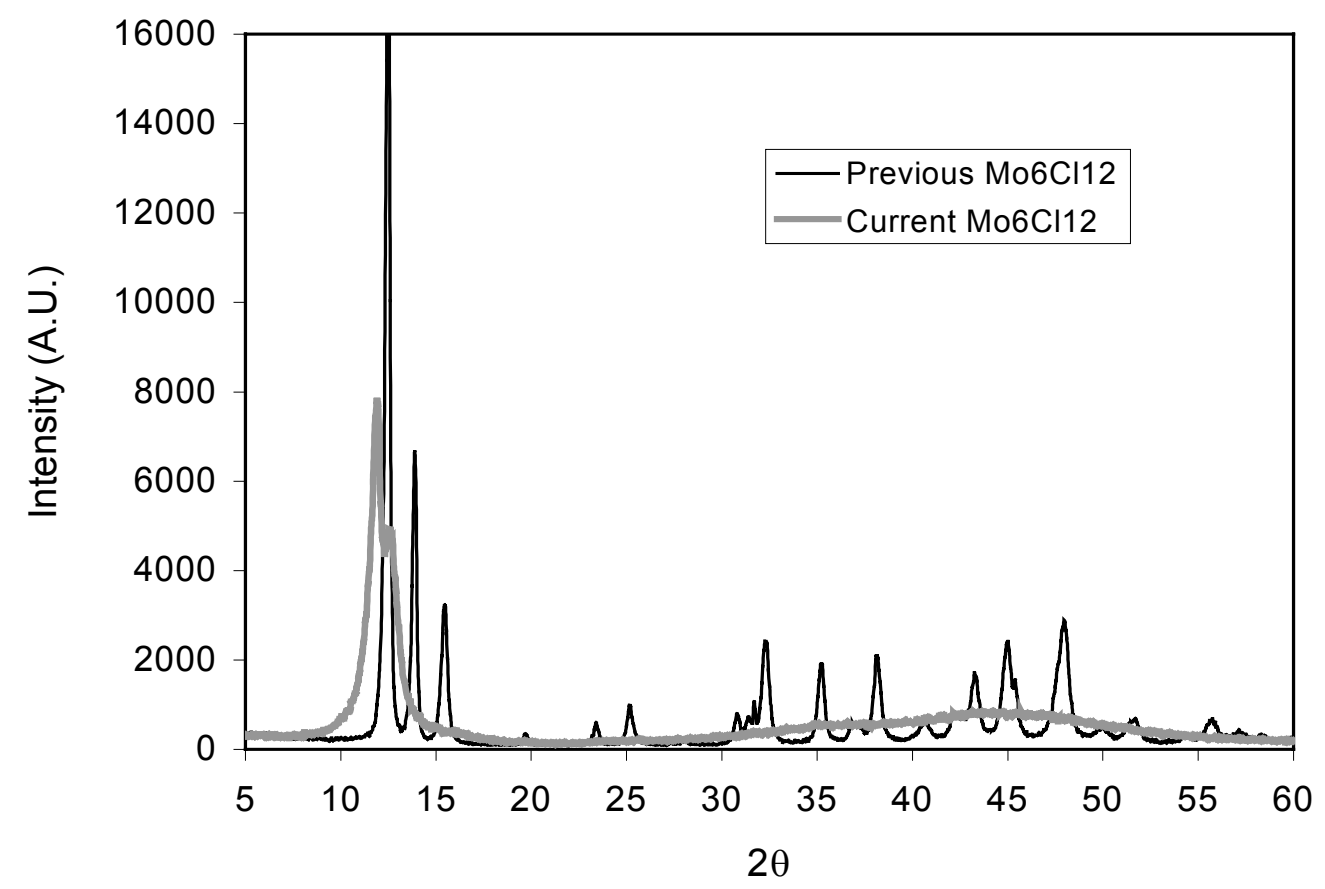

Figure 3. X-ray powder diffraction patterns of current $\mathrm{Mo}_{6} \mathrm{Cl}_{12}$ and previously synthesized $\mathrm{Mo}_{6} \mathrm{Cl}_{12}$.

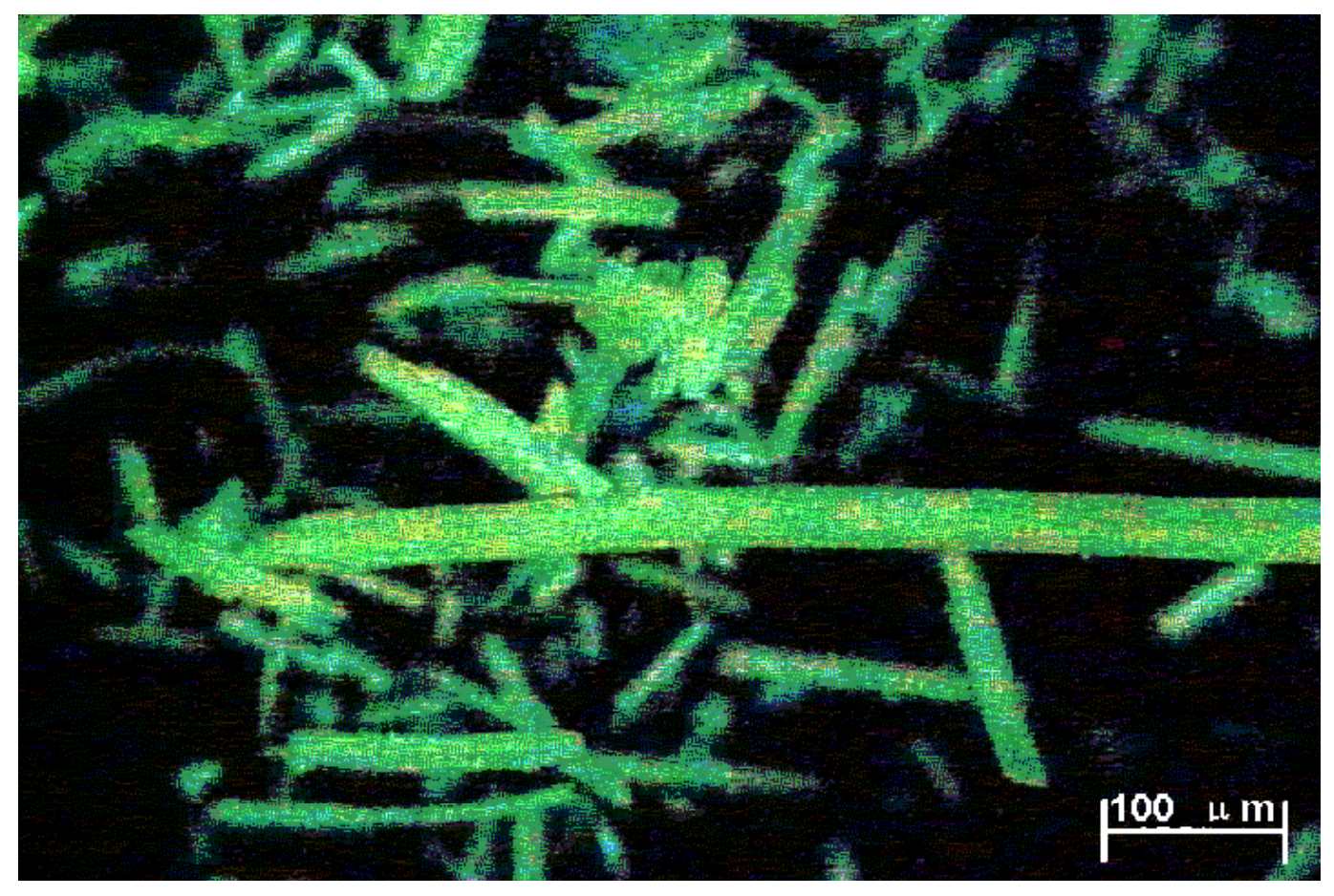

Figure 4. Optical microscope image of currently synthesized $\mathrm{Mo}_{6} \mathrm{Cl}_{12}$. 


\section{Quartz Sample Cell for High Temperature Spectroscopy}

A quartz sample cell for performing absorption and emission spectroscopy on thin films of $\mathrm{Mo}_{6} \mathrm{Cl}_{12}$ in a controlled gas environment at elevated temperatures was designed as shown in Figure 5. The first prototype was fabricated by the glass shop. The lower portion of the sample cell consists of a standard 10mm square Spectrocil quartz fluorimeter cell from Starna Cells. By means of a quartz to glass transition, a flat O-ring joint is attached to the upper portion of the quartz fluorometer cell, which allows for access to the sample. A square quartz tube is attached to the top member of the O-ring joint. This tube is used as both the gas inlet and to provide mechanical support to the "sample assembly". The gas flows across the sample, exiting from a second square tube attached to the top member of the O-ring joint. The spectroscopy will be performed in a "flow-through" or "static" gas ambient, depending on the application.

Thin films of $\mathrm{Mo}_{6} \mathrm{Cl}_{12}$ will be coated on an UV substrate that does not fluoresce in the UV and has good thermal conductivity. We are experimenting with alumina and sapphire to determine the optimum material. Up to three Pt thin film heaters will be attached to the backside of the substrate using a high temperature Ag paste. The sample-substrateheater assembly, referred to as "sample assembly" will be mechanically secured to the gas inlet tube. Not shown in the figure are two electrical leads for powering the heaters. Tests of the platinum heaters indicated the need to re-design the electrical connections.

As shown in the cross-sectional view of the quartz cell, the sample will be positioned along the diagonal of the cell to allow for $90^{\circ}$ fluorescence measurements. The quartz sample cell is mounted in a metal support structure that allows for $\mathrm{x}-\mathrm{y}-\mathrm{z}$-phi positioning to optimize the luminescence collection efficiency from the $\mathrm{Mo}_{6} \mathrm{Cl}_{12}$ thin films. The entire quartz cell and support structure is housed inside an optically dark spectrometer compartment with provisions for both gas and electrical feedthroughs. 


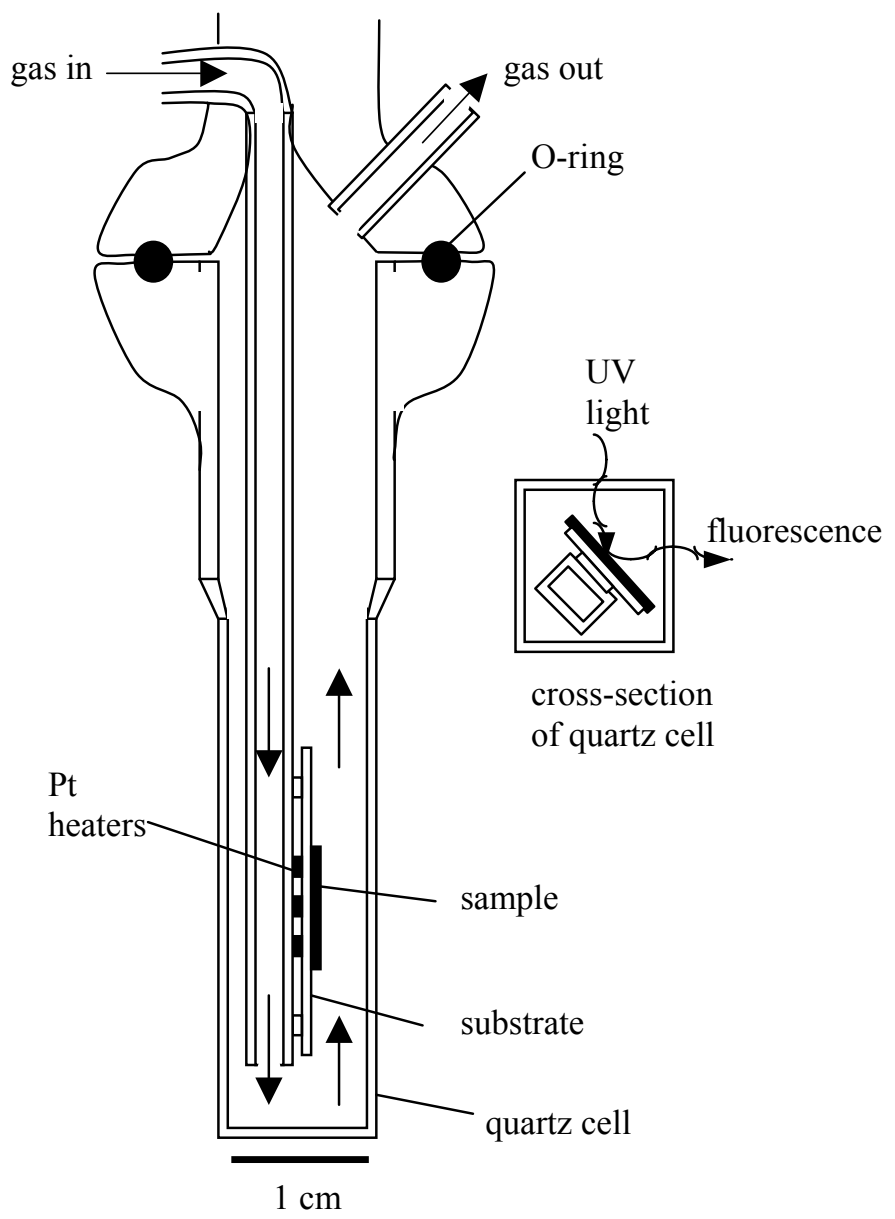

Figure 5. Schematic sketch of the set up for making absorption and emission measurements on thin films of $\mathrm{Mo}_{6} \mathrm{Cl}_{12}$ in a controlled gaseous ambient and fixed temperature (up to at least $200{ }^{\circ} \mathrm{C}$ ). The $\mathrm{Mo}_{6} \mathrm{Cl}_{12}$ thin film (sample) is coated on a substrate with up to three backside resistive $\mathrm{Pt}$ heaters. Not shown are the electrical leads for powering the heaters. 


\section{CONCLUSIONS}

Though the compound synthesized is not the same previously synthesized by $\mathrm{x}$-ray powder diffraction, the absorption and emission spectra indicate similar properties. More investigation is needed in order to determine what happened during the synthesis to give the different compound structure. The emission calibration standard needs to be changed in order make sure that the peak maximum is correct - this is currently underway.

\section{REFERENCES}

[1] R. D. Mussell, Thesis, Michigan State University, 1988

[2] M. D. Newsham, Thesis, Michigan State University, 1988

[3] C. J. Ruud, Thesis, Michigan State University, 1999

[4] R. N. Ghosh, G. L. Baker, C. J. Ruud, D. G. Nocera, Appl. Phys. Lett., 75, 2885 (1999)

[5] Remillard, J.T.; Jones J.R.; Poindexter, B.D.; Narula, C.K.; and Weber, W.H., Applied Optics, 38, no. 25, 5306 (1999)

[6] H. Schafer et al, Z. Anorg. Allg. Chem., 353, 281 (1967)

[7] H. G. Von Schnering, W. May, K. Peters, Zeitschrift fur Kristallographie, 208, 386 (1993)

[8] B. D. MacCraith et al., J. Sol-Gel Sci. and Tech., 8, 1121 (1997)

[9] B. D. MacCraith et al., J. Non-Crystal. Sol., 306, 138 (2002)

\section{BIBLIOGRAPHY}

None.

\section{LIST OF ACRONYMS AND ABBREVIATIONS}

$\mathrm{MeOH}$ - Methanol

$\mathrm{CH}_{3} \mathrm{CN}$ - Acetonitrile 


\section{APPENDIX A}

The following tasks from the "Statement of Project Objectives" were performed during this reporting period:

PHASE I - October, 2002 - December, 2003

\section{Task 1.0 -- Establish processing conditions / prove concept}

Subtask $1.1 \quad \mathrm{Mo}_{6} \mathrm{Cl}_{12}$ synthesis (Oct. 2002 - March 2003)

We estimated that $\sim 5$ grams of $\mathrm{Mo}_{6} \mathrm{Cl}_{12}$ will be needed to support the project. To date 4 grams have been synthesized and purified, and an additional 5 grams will be available by 31 March. Initial tests for $\mathrm{Mo}_{6} \mathrm{Cl}_{12}$ purity are being augmented by x-ray diffraction, and comparison of the cluster's spectroscopic characteristics in solution with authentic spectra.

Subtask 1.2 Thin film preparation (April 2003 - Sept. 2003)

We initiated work on preparing thin film sol-gel matrices for $\mathrm{Mo}_{6} \mathrm{Cl}_{12}$. We are investigating two approaches for depositing the films, a simple dipping scheme, and a "spray-on" approach.

Subtask 1.4 Characterization of luminescence (Oct. 2002 - Dec. 2003)

A quartz sample cell for performing spectroscopy was designed. The first prototype was fabricated by the glass shop followed by initial testing. The cell allows for (i) measurements in either a flow-through or static gas ambient with simultaneous (ii) heating of thin films supported on quartz slides and (iii) x-y-z-phi positioning to optimize the luminescence collection efficiency from the thin films. Tests of the platinum heater indicate the need to re-design the electrical wiring. 